Addendum 1951 to the British Pharmacopœia 1948 (Published under the direction of the General Medical Council.) Official from September 1, 1951. Pp. xviii+114. (London: Constable and Co., Ltd., 1951.) 17s, 6d. net.

7 HE rapid advance of pharmacology makes it essential that the pharmacopcias of the world shall be published more frequently than before. It is hoped that the "British Pharmacopœeia" will now be published at intervals of five years ; but even this is not enough, and it will probably always be necessary to publish addenda to bring the old Pharmacopoeia up to date while the new one is coming to birth. The $195 \mathrm{I}$ addendum to the "British Pharmacopoia" contains fifty-two new monographs dealing with such substances as chloramphenicol, dicophane (DDT), dihydrostreptomycin, dimercaprol (BAL), mepyramine (neoantergan), oxophenarsine, proguanil ('Paludrine'), quinalbarbitone (seconal), sulphadimidine (sulphadimethylpyrimidine), tubocurarine, and various vaccines and preparations of human blood.

One of the most important duties of the Pharmacopceia Commission is to devise official names for new drugs. The fruits of its work in this field generally appear first as "Approved Names" for unofficial drugs, which are eventually admitted to the Pharmacopoeia itself. The choice of names is complicated by the desirability of keeping in step with the Americans, who are engaged upon the same pursuit, and is sometimes limited by the fact that a number of manufacturers have chosen all the best names and taken legal action to prevent other people using them. These are some of the difficulties; the result is not uniformly successful. Tho Commission was in happy mood when it approved of 'sulphadimidine', but it is unfortunate that it was driven to approve of 'tripelennamine', which is too long and presumably owes its origin to the unspecific fact that its full chemical name contains the letter ' $n$ ' repeated three times (if not four). The teachers of pharmacology must learn these new names themselves, teach them to their students, and persuado their clinical colleagues to use them instead of the confusing collection of seductive trade names, many of which refer to the same substance. The ease with which these various tasks can be accomplished depends on the success of the Commission in choosing official names which are euphonious and brief. Each new list of approved names is received with mixed emotions by those who will have to use them.

$$
\text { J. H. G. }
$$

Moderne Biologie

Festschrift zum 60 Geburtstag von Prof. Dr. Hans Nachtsheim. Herausgegeben von H. Grüneberg und W. Ulrich. Pp. $288+5$ plates. (Berlin: F. W. Peters, 1950.) n.p.

THIS volume, edited by H. Grüneberg of London and W. Ulrich of Berlin-Dahlem, is the "Festschrift" marking the sixtieth birthday of Prof. Hans Nachtsheim, the distinguished German geneticist who is now professor of general biology and genetics and director of the Institute of Genetics of the Free University of Berlin (necessarily in the Western and not the Eastern Zone of that city). The introductory chapter by Ulrich tells of Prof. Nachtsheim's career and of the importance of his work, which began with a paper in 1912 on the cytology of sex determination in the honey bee, and continued with a long series of one hundred papers on the geneties and physiology of a wide range of organisms-principally Drosophila, the rabbit, the pig, man himself, and an extraordinarily wide array of other material. His latest paper concerns the Pelger-anomaly in man and rabbit-a Mendelian character of the nuclei of the leucocytesand was published in 1950 in the Journal of Heredity.

The contributed papers are twenty in number, and, as is to be expected, contain authoritative accounts of the recent work of many writers, principally but not exclusively German, whose works are not easily accessible in Great Britain. A wide range of biological territory is covered in developmental genetics, general zoology, anthropology, animal psychology and evolution. In works of this nature it is scarcely possible to single out many individual contributions for special comment. Those interested in modern aspects of evolution will welcome Sewall Wright's essay "Population Structure as a Factor in Evolution", which summarizes his more recent ideas. Of importance to animal psychologists is the paper by $\mathrm{K}$. Herter, "Vom Lernvermögen der Fische". The genetical basis of polyembryony in plants is of great practical significance to plant breeders, and is discussed by H. Kappert.

As a book of both general and special biological interest, this is a noteworthy addition to recent biological literature.

S. C. Hartand

\section{Advances in Electronics}

Edited by L. Marton. Vol. 2. Pp. $x+378$. (New York: Academic Press, Inc., 1950.) 7.60 dollars.

$7 \mathrm{HE}$ second of what is apparently intended to be an annual series, this book presents a number of review articles by both American and European authors. The topics covered are as follows : progress in the past decade in the manufacture and design of cathode ray tubes; electron lenses; field plotting and ray tracing in electron optics ; cathodoluminescence; intrinsic dielectric breakdown in solids; the microwave magnetron; ferromagnetic phenomena at microwave frequencies; and microwave spectroscopy. All the articles are of a high standard and form useful surveys of the present state of knowledge in their respective fields.

\section{Electron-Tube Circuits}

By Prof. Samuel Seely. (McGraw-Hill Electrical and Electronic Engineering Series.) Pp. ix +529 . (New York and London: MeGraw-Hill Book Co., Inc., 1950.) $57 s$.

7 HIS volume forms one of the McGraw-Hill Electrical and Electronic Engineering Series; and, as the author states, it is the outgrowth of several courses, organized by him, on electron-tube circuits and applications covering many important types of equipment and instruments in widespread use during the Second World War.

The subject-matter falls into a number of major sections. The first of these is a review of the fundamental properties of electron tubes and their basic circuit applications. The second part of the book contains a discussion of untuned amplifiers and circuits, including a chapter on arrangements which are particularly important in analogue computers, while the third part deals similarly with tuned amplifiers and oscillators. Next there is a comprehensive treatment of power rectifiers, filters and regulators, which is followed by a discussion of amplitude modulation and demodulation and frequency modulation and detection. Finally, there is a section on circuits of a kind developed extensively during the War for use in 